\title{
Development of Microbial-Human Enterocyte Interaction: Cholera Toxin
}

\author{
LEI LU, MANUEL E. BALDEON, TOR SAVIDGE, CHARALABOS POTHOULAKIS, AND \\ W. ALLAN WALKER \\ Developmental Gastroenterology Laboratory, Massachusetts General Hospital [L.L., T.S., W.A.W.]; \\ Division of Gastroenterology, Beth Israel Deaconess Medical Center [C.P.]; and Department of \\ Pediatrics, Harvard Medical School [W.A.W.], Boston, Massachusetts 02129, U.S.A.; and Programa de \\ Alimentos y nutricion, Universidad San Francisco de Quito, Circulo Cumbaya, Quito, Ecuador [M.E.B.]
}

\begin{abstract}
Diarrhea in infants and children is a major health hazard worldwide. Certain toxigenic diarrheas occur more commonly and are manifested more severely during the neonatal period. We have previously studied the regulation of cholera toxin-induced secretion in animal models during development. In those studies we have shown that cholera toxin stimulates a much greater secretion by immature compared with mature small intestine, and the mechanism appears to be an up-regulation of postreceptor signal transduction molecules (adenyl cyclase and $\mathrm{G}_{\mathrm{s} \alpha}$ ) leading to an elevated cAMP level. In this study, using experimental models of human intestinal development (fetal cell lines, a micro-Ussing chamber, organ cultures, and fetal intestinal xenograft transplants), we provide preliminary evidence that cholera toxin induces an enhanced secretion mediated in part by a developmental up-regulation of the cAMP response in immature versus mature human small intestine. Additional studies are needed, however, to further define whether other developmental
\end{abstract}

ABSTRACT

events (e.g. receptor expression) also regulate cholera toxinenterocyte-enhanced interaction. Nonetheless, this approach to determining the role of development in the pathophysiology of cholera in infants may help in strategies to prevent and treat this condition and other age-related intestinal infectious diseases. (Pediatr Res 54: 212-218, 2003)

Abbreviations
CT, cholera toxin
$\boldsymbol{I}_{\mathbf{s c}}$, short circuit current
$\mathbf{T}_{\mathbf{8 4}}$, a human colonic cancer cell line
$\mathbf{H}_{\mathbf{4}}$, a primary human fetal crypt small intestinal cell line
tsHFIE, a temperature-sensitive, conditionally immortalized
human fetal intestinal epithelial villous cell line
PGE $_{\mathbf{2}}$, prostaglandin $\mathrm{E}_{2}$
SCID, severe combined immunodeficiency
CFTR, cystic fibrosis transmembrane conductance regulator

Diarrheal disease constitutes one of the major causes of morbidity and mortality in infants and young children on a global scale (1). We know from clinical and laboratory studies that certain toxigenic diarrheas occur more commonly and are manifested more severely in the neonatal period (2). Toxigenic diarrhea is caused by a bacterial exotoxin binding to an enterocyte receptor and the activation of a signal transduction pathway leading to enhanced secretion and decreased fluid absorption (3). Our laboratory has had a long-standing interest in developmental factors affecting CT-induced diarrhea as a paradigm for microbial-epithelial "cross talk" in the developing small intestine. We have provided evidence that there is a

Received October 2, 2002; accepted February 28, 2003.

Correspondence: W. Allan Walker, M.D., Combined Program in Pediatric Gastroenterology and Nutrition, Harvard Medical School, Director, Developmental Gastroenterology Laboratory, Massachusetts General Hospital, 114 16th Street (114-3503), Charlestown, MA 02129-4404, U.S.A.; e-mail: wwalker@partners.org

Supported by grants from the National Institutes of Health T32-DK07477 (L.L.); R37-HD12437; R01-HD31852; P01-DK33506; P30-DK40561 (W.A.W.)].

DOI: 10.1203/01.PDR.0000074974.21797.83 striking difference in host responsiveness to CT as measured by fluid accumulation in intestine loops from preweaned rats when compared with loops from mature (postweaned) animals (4). A similar increased sensitivity to Escherichia coli heat-stable enterotoxin in immature animals and man was reported by Cohen et al. (5). The mechanism of this excessive secretory response to $\mathrm{CT}$ in the immature rat intestine was not because of an increased number of toxin receptors on the apical surface as was expected and could only partially be explained by an increased receptor affinity (6). We subsequently demonstrated increased enterocyte sensitivity to CT-induced adenylate cyclase activation as the basis for cAMP-mediated enhanced secretion (7). We further reported that pretreatment of the immature rat intestine with cortisone, an intestinal trophic factor, caused a change in CT-induced secretion toward a mature response (4). These results suggested that an immaturity of enterocytes and their signaling machinery may be the basis for the enhanced developmental CT response.

Despite the advances in understanding the molecular mechanisms of action of $\mathrm{CT}$, cholera remains a major international 
health problem. Furthermore, the CT-induced secretory effect on the gut has proven to be more complex than originally envisioned (8). In addition, extrapolating events (mechanisms) of response from animal models of development to presumed events in the developing human intestine may not be valid. Accordingly we have begun to study CT interaction with the developing human small intestine to determine whether a similar effect of CT existed in the human intestinal immature gut and whether the effect was mediated in part by developmental regulation of postreceptor events. This approach should be helpful in defining the developmental regulation of human enterocyte interaction with luminal pathogens and their exotoxins in general, as well as in establishing its relationship with the pathogenesis of age-related gastrointestinal infectious diseases.

Thus, in this study, we have extended the observations reported on the interaction of $\mathrm{CT}$ with animal models of developing small intestine $(2,4,7)$ to begin to define CT interaction with the developing human gut. This laboratory has either established or validated several experimental models of the developing human small intestine to study their interaction with luminal microorganisms and their exotoxins. These models include a micro-Ussing chamber technique to study $\mathrm{Cl}^{-}$ secretion (9), two human fetal small intestinal cell lines (10, 11) to define postreceptor signaling events, and organ culture (12) and a human fetal intestine xenograft model (13) to confirm the initial results made in other models. Using these techniques collectively we now provide the first preliminary evidence that the immature human small intestine also responds excessively to $\mathrm{CT}$ and the excessive response maybe caused in part by a developmental up-regulation of postreceptor signal-transduction events, (e.g. cAMP).

\section{METHODS}

Reagents. CT, $\mathrm{PGE}_{2}$, and 5-nitro-2-(3-phenylpropylamino) benzoic acid were obtained from Calbiochem Laboratory (San Diego, CA, U.S.A.). Tissue culture reagents were obtained from Invitrogen (Carlsbad, CA, U.S.A.). Other chemicals, if not specified, were purchased from Sigma Chemical Co. (St. Louis, MO, U.S.A.).

Animals. Female Sprague-Dawley rats were purchased from Taconic (Germantown, NY, U.S.A.) between 16 to 18 days of gestation. Animals were kept in an institutional animal facility with a 12-h light-dark cycle. They were fed rat chow and water ad libitum. This study has been approved by the Subcommittee on Research Animal Care at Massachusetts General Hospital. Experiments were performed when the litters were $2 \mathrm{wk}$ of age for the preweaned group and $4 \mathrm{wk}$ of age for the postweaned group. Half of the litters were sacrificed at $2 \mathrm{wk}$ and the other half weaned at $3 \mathrm{wk}$ and sacrificed at $4 \mathrm{wk}$. Adult animals were sacrificed at $10 \mathrm{wk}$.

$\mathbf{I}_{\mathrm{sc}}$ measurements. The $I_{s c}$ across the intestinal epithelium of rat small intestine was measured according to procedures previously described (14) with modifications. Briefly, preweaned rat small intestinal mucosa was directly mounted on micro-Ussing chambers (Physiologic Instruments, San Diego, CA, U.S.A.) with an exposed area of $0.22 \mathrm{~cm}^{2}$, and postweaned and adult rat small intestines were gently stripped of the serosal layer without disrupting the mucosal surface and then mounted on chambers with an exposed area of $0.4 \mathrm{~cm}^{2}$. Human fetal small intestine obtained from 20 -wk-old fetuses were stripped of the serosal layer and mounted onto a micro-Ussing chamber as described above. Biopsy tissues obtained from pediatric patients during endoscopy were carefully mounted onto a micro-Ussing chamber under the dissecting microscope and bathed in an oxygenated buffer as described (9). The results of micro-Ussing chamber studies were included only if the fetal intestinal or intestinal biopsy specimens from infants and children were morphologically normal and the fetus, infant, or child was free of gastrointestinal disease diagnosis. Both apical and basolateral surfaces were bathed in Ringer's solution. The composition of the media used was (in $\mathrm{mM}$ ): $\mathrm{NaCl}, 113 ; \mathrm{KCl}$, 4.7; $\mathrm{MgSO}_{4}, 1.2 ; \mathrm{CaCl}_{2}, 1.9 ; \mathrm{NaHCO}_{3}, 25$; and glucose, 12.1 . The bathing solutions were maintained at $37^{\circ} \mathrm{C}$ and oxygenated with $95 \% \mathrm{O}_{2}$ and $5 \% \mathrm{CO}_{2}$ to optimize oxygen supply to the tissue and to maintain the $\mathrm{pH}$ at 7.4.

After mounting, each preparation was connected to a voltage clamp (Physiologic Instruments) with current and electrodes placed on either side. To compensate for fluid resistance, preparations were clamped to zero potential difference and were allowed to equilibrate for 20-40 min until a steady-state basal $I_{s c}$ was achieved. The apical surface was incubated with CT $(1 \mu \mathrm{g} / \mathrm{mL})$ or buffer alone, and the $I_{s c}$ was measured at 5-min intervals for $60 \mathrm{~min}$. In each case, the control (medium alone) response was compared with the response achieved in the presence of CT. In some experiments to assess ongoing tissue viability, glucose $(25 \mathrm{mM})$ was added to the apical surface of the tissue at the end of CT treatment, and the $I_{s c}$ change was recorded.

Maintenance of cell cultures. $\mathrm{H}_{4}$ cells, developed in our laboratory (10), are nontransformed human fetal primary small intestinal epithelial cells that are comparable to the IEC-6 rodent crypt cell line (15). $\mathrm{H}_{4}$ cells were routinely maintained in plastic culture flasks with Dulbecco's modified Eagle medium, supplemented with $10 \%$ FCS, $20 \mathrm{mM}$ L-glutamate, and human recombinant insulin $(0.5 \mathrm{U} / \mathrm{mL})$. A temperaturesensitive, conditionally immortalized human fetal small intestinal cell line [tsHFIE (11)] was generously supplied by Dr. Andrea Quaroni, Department of Biology, Cornell University (Ithaca, NY, U.S.A.). This human fetal enterocyte cell line was originally developed and characterized by Quaroni and Beaulieu (11) using a stable transfection of 13-wk human fetal enterocytes with a temperature-sensitive large $\mathrm{T}$ antigen DNA from the simian virus attached to an enterocyte-specific promoter and a retroviral vector. At $33^{\circ} \mathrm{C}$ these cells function as transformed enterocytes, and at $39^{\circ} \mathrm{C}$ the $\mathrm{T}$ antigen is inactivated and cells undergo differentiation and function as primary villous enterocytes. The tsHFIE cells were routinely maintained in Dulbecco's modified Eagle medium, supplemented with $10 \%$ FCS and $20 \mathrm{mM} \mathrm{L-glutamate}$ at $33^{\circ} \mathrm{C}$ on 12 -well tissue culture plates. On confluency, cells were changed to the media containing $1 \mu \mathrm{M}$ dexamethasone and incubated at $39^{\circ} \mathrm{C}$ for $1 \mathrm{wk}$ to inactivate the large $\mathrm{T}$ antigen and induce differentiation. $\mathrm{T}_{84}$ cells, obtained from American Type Culture Collection (Washington, D.C, U.S.A..), were routinely maintained 
in plastic culture flasks containing minimal essential mediumF12 HAM, supplemented with $10 \%$ FCS and $20 \mathrm{mM} \mathrm{L}-$ glutamate. $\mathrm{T}_{84}$ cells were trypsinized after becoming confluent using a $0.25 \%$ trypsin- $0.5 \mathrm{mM}$ EDTA solution and reseeded at one fifth the original density onto collagen-coated filter inserts (Transwell, Corning, NY, U.S.A.). $\mathrm{T}_{84}$ cells form a polarized monolayer when grown on these filters.

cAMP extraction from human fetal small intestine xenografts and biopsy samples. Human fetal small intestine xenografts were supplied by the Xenograft Core Facility in of our laboratory. Briefly, fetal small intestine from 16- to 20-wk fetuses was transplanted s.c. into SCID mice and kept in a pathogen-free environment for 6 mo as previously reported (13). We have shown in several recent publications $(16,17)$ that fetal tissue transplanted into SCID mice reepithelializes and matures in a manner similar to that in the intrauterine environment as determined by microvillous disaccharidases and other enzymes. Accordingly, when studied the xenograft small intestinal samples are as viable as intestinal biopsy samples. Tissues were obtained by carefully removing all the serosal and muscle tissues surrounding the intestinal mucosa and cut into small pieces using a surgical blade. Human biopsy tissue from children undergoing diagnostic endoscopy for abdominal complaints was obtained. If the tissue appeared normal under the dissecting microscope and no gastrointestinal diagnosis was made, it was processed for study and maintained in $95 \%$ oxygenated culture media until transferred to the laboratory. Only data from specimens subsequently noted to be normal morphologically were included in the study. Fetal tissue and intestinal biopsies were obtained with the approval of the Partners Human Study Committee and with parental signed permission. After exposure to $\mathrm{CT}$ or media under conditions previously used in cells, tissues were homogenized with a handheld polytron. The homogenized mixture was spun briefly, the supernatant was loaded onto trimethylaminopropyl SAX minicolumns (Amersham, Little Chalfond, Buckinghamshire U.K.), and cAMP was extracted with methanol according to the manufacturer's recommendation.

Measurement of intracellular cAMP levels. Cell lines were grown to confluence and incubated with various concentrations of CT in Hanks' balanced salt solution for $1 \mathrm{~h}$. Tissues either from xenografts or biopsies were cut into small pieces and incubated with CT or media alone for $2 \mathrm{~h}$. At the end of incubation period, cells were washed three times with cold PBS, and $500 \mu \mathrm{L}$ of lysis buffer (Amersham) was added to each well. The cell lysates were collected and stored at $-20^{\circ} \mathrm{C}$ if not measured immediately. Tissues were snap-frozen in liquid nitrogen and stored at $-20^{\circ} \mathrm{C}$ until further analysis. Cellular cAMP levels were measured using a commercially available enzyme immunoassay kit (Amersham Biotrak), normalized with the total protein content and expressed as picomoles per milligram protein. Protein concentrations were determined using a Bio-Rad protein assay kit with BSA as the standard (BioRad, Hercules, CA, U.S.A.).

Statistics. Data are presented as the mean \pm SEM. Statistics were performed with StatView (version 4.5; SAS Institute, Cary, NC, U.S.A.) using either an unpaired $t$ test or ANOVA. A $p<0.05$ was considered statistically significant for the $t$ test and $p<0.0033$ for the Dunn test (a cutoff of $p<0.0033$ is mandated by the StatView program for this test).

\section{RESULTS}

\section{CT-Induced Chloride Secretion in the Developing Small Intestine}

Rat studies. In this study, we have begun to use a microUssing chamber technique (9) to measure chloride secretion in human small intestinal models. To validate this technique as an appropriate measurement of the CT response, we first tested it in preweaned and postweaned rats as a model for agedependent differences in chloride secretion in response to CT (Fig. 1). The addition of CT compared with control media to the apical membrane surface of preweaned rats resulted in a significant increase in $I_{s c}$ (Fig. $1 A$ ) with time, reaching a peak at $60 \mathrm{~min}$. As reported previously in the in vivo loop model (4), CT induced a significantly higher secretory response in preweaned compared with postweaned and adult rats as measured by $I_{s c}$ during $60 \mathrm{~min}$ (Fig. $1 B$ ). The $I_{s c}$ change was noted to diminish after the addition of the chloride-channel inhibitor, 5-nitro-2-(3-phenylpropylamino) benzoic acid, to the bathing solution (data not shown). These studies confirmed that preweaned rats were more responsive to $\mathrm{CT}$ than postweaned rats using the micro-Ussing chamber technique. To further define an age-related effect on chloride secretion in preweaned and postweaned rats, $\mathrm{PGE}_{2}(10 \mu \mathrm{M})$, known to induce chloride secretion from intestinal epithelia, was added to the solution bathing the basolateral surface of micro-Ussing chambers (Fig. $1 B$, insert). A $\mathrm{PGE}_{2}$-stimulated $I_{s c}$ response had a mean increase of $15.9 \pm 4 \mu \mathrm{A} / \mathrm{cm}^{2}$ in preweaned compared with15.4 $\pm 9 \mu \mathrm{A} / \mathrm{cm}^{2}$ in postweaned rats, suggesting no age-dependent difference.

Human studies. Having validated the micro-Ussing chamber technique to measure CT-induced chloride secretion in preweaned and postweaned rats, we next performed comparable studies on fetal (immature) small intestine and on (mature) small intestinal biopsies from children. In six separate experiments, fetal intestine from 16- to 20-wk aborted fetuses was compared with small intestinal biopsies from infants or children exposed to CT $(1 \mu \mathrm{g} / \mathrm{mg})$ apically. Each comparative experiment showed a greater rise in $I_{s c}$ with time for fetal tissue compared with tissue from infants or children. Inasmuch as each experiment was a unique observation, the six experiments cannot be compared statistically. Accordingly, Figure $2 A$ is a representative example of these six observations on $I_{s c}$. To assure continued viability of the biopsy after CT stimulation, we exposed tissue to glucose. Figure $2 B$ shows the $I_{s c}$ after glucose infusion. These experiments strongly suggest that the immature human small intestine, like that of preweaned rats, is more sensitive to CT than the mature intestine.

\section{cAMP Response to CT}

Human cell lines. Having demonstrated a excessive developmental secretory response to CT in human immature versus mature small intestine similar to that noted in our animal models using micro-Ussing chambers, we next determined 
A

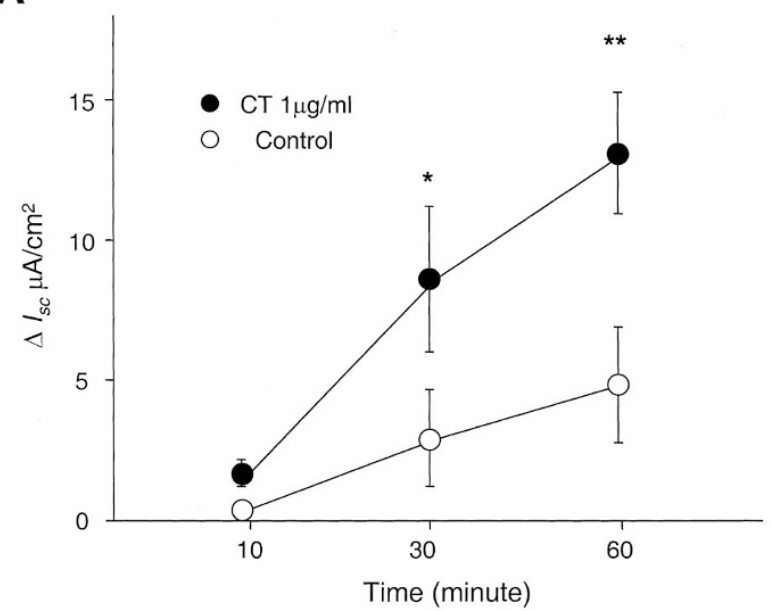

B

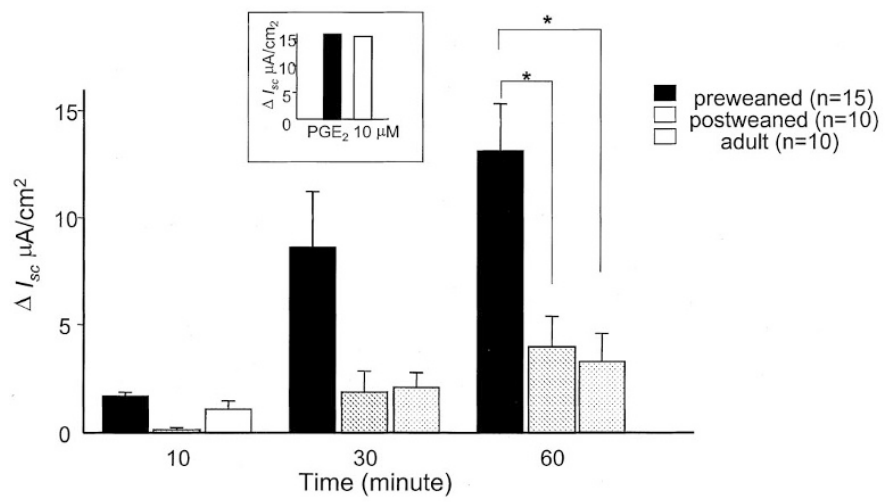

Figure 1. $A$, effect of $\mathrm{CT}$ on percent change of $I_{s c}$ in preweaned rat small intestine mucosa. CT $(\mathbf{\bullet} ; 1 \mu \mathrm{g} / \mathrm{mL})$ was added to apical membranes mounted on micro-Ussing chambers. Control $(\bigcirc)$ tissues indicate change in $I_{s c}$ with time. Secretion is expressed as a change in $I_{s c}$ from baseline. Each point represents the mean $\pm \operatorname{SEM}(n=15) *{ }^{*} p<0.05, * * p<0.01 . B$, effect of CT on $I_{s c}$ percent change of small intestinal mucosa of preweaned $(\square ; n=15)$, postweaned (慻; $n=10$ ), and adult $(\square ; n=10)$ rats. Rat small intestinal mucosa was mounted onto micro-Ussing chambers and apical surface was exposed to CT $(1 \mu \mathrm{g} / \mathrm{mL})$. Chloride secretion is expressed as $I_{s c}$ change from baseline. Each bar is the mean \pm SEM. $* p<0.0033$ by ANOVA Dunn test. Inset, response after $\mathrm{PGE}_{2}(10 \mu \mathrm{M})$ stimulation. There is no difference in the $I_{s c}$ response between preweaned ( $\square$ ) and postweaned $(\square)$ rat small intestine after $\mathrm{PGE}_{2}$ stimulation.

whether the excessive secretory response was in part related to a post-CT receptor signal-transduction reaction as previously reported in animal models $(6,18)$. Because CT-induced chloride secretion is mediated via the cAMP pathway, we determined levels of cAMP in the two human fetal cell lines $\left(\mathrm{H}_{4}\right.$ and tsHFIE) compared with a more mature human transformed cell line, $\mathrm{T}_{84}$. In Figure 3, we show a significant difference in the cAMP response to $\mathrm{CT}$ between $\mathrm{H}_{4}$ and tsHFIE (immature human enterocytes) and $\mathrm{T}_{84}$ cells (representative mature human enterocytes). CT was noted to stimulate a dose-dependent increase of cellular cAMP production after 1-h exposure in these cells compared with media alone. Moreover, there was a significantly higher level of CT-induced cAMP in $\mathrm{H}_{4}$ and tsHFIE cells compared with $\mathrm{T}_{84}$ cells (Fig. $3 A$ ). The basal levels of cellular cAMP in $\mathrm{H}_{4}$, tsHFIE, and $\mathrm{T}_{84}$ were $17.8 \pm$
A

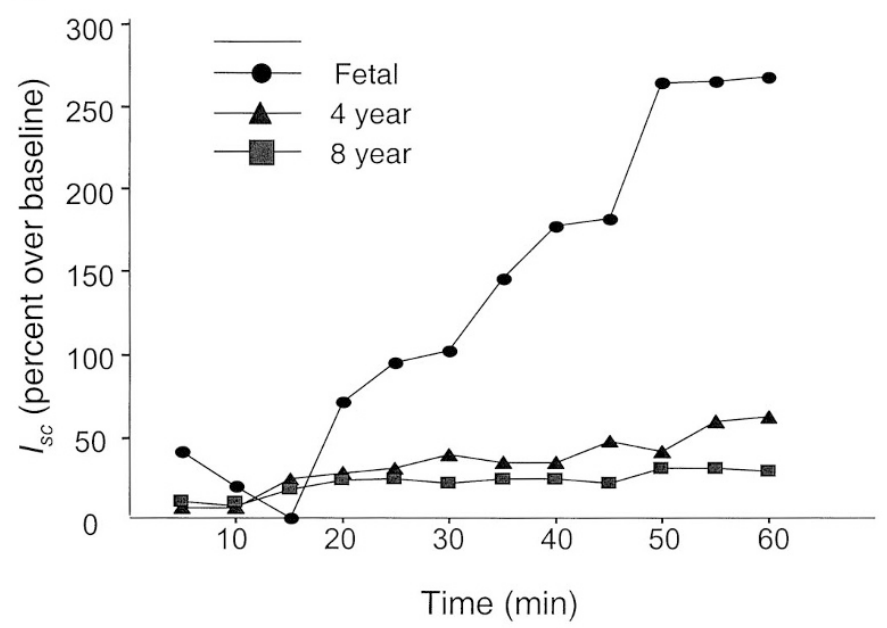

B

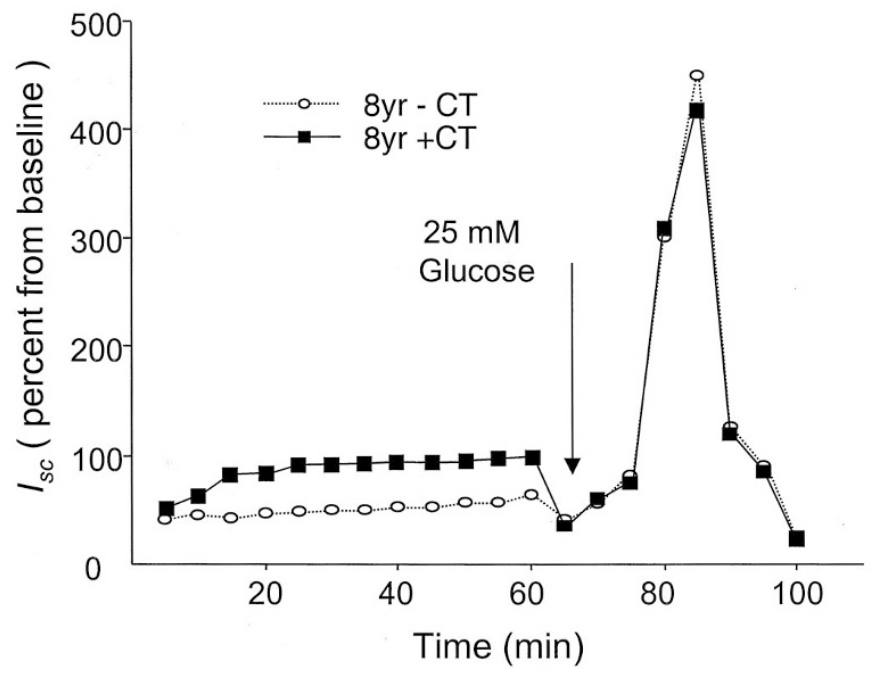

Figure 2. $A$, effect of $\mathrm{CT}$ on $I_{s c}$ on percent change of fetal duodenal intestinal tissue and in normal duodenal biopsies from children. A 20 week-old fetal duodenal mucosa ( $-\longrightarrow$ ) and duodenal biopsies from a 4-year-old $(\longrightarrow)$ and an 8-year-old (- - ) child were mounted onto a micro-Ussing chamber and exposed to CT $(1 \mu \mathrm{g} / \mathrm{mL})$. Each point is expressed as a change in $I_{s c}$ as a percent of baseline. Six experiments that compared 20-wk-old fetal small intestine with various aged pediatric small intestine biopsies were performed independently. This tracing is representative of these six experiments. $B$, test of sustained tissue viability in micro-Ussing chamber after CT stimulation demonstrating the response of small intestinal biopsies from 8-year-old child mounted in a micro-Ussing chamber to glucose $(25 \mathrm{mM})$ after the test period with (- - ) or without (- - $)$ CT stimulation $(60 \mathrm{~min})$. The $I_{s c}$ response to glucose suggests that the intestine studied remains viable during the test period.

$2.8,11.8 \pm 3.3$, and $6.0 \pm 1.1 \mathrm{pmol} / \mathrm{mg}$, respectively. The mean difference in cAMP levels after $\mathrm{CT}$ stimulation between $\mathrm{H}_{4}$ and $\mathrm{T}_{84}$ cells or tsHFIE and $\mathrm{T}_{84}$ cells was 88.7 and $86.0 \mathrm{pmol} / \mathrm{mg}(p<0.01)$ with $0.1 \mu \mathrm{g} / \mathrm{mL} \mathrm{CT}, 122$ and $142.7 \mathrm{pmol} / \mathrm{mg}(p<0.01)$ with $1 \mu \mathrm{g} / \mathrm{mL} \mathrm{CT}$, and 59.8 and 129 $\mathrm{pmol} / \mathrm{mg}(p<0.01)$ with $10 \mu \mathrm{g} / \mathrm{mL}$ CT. When the fold increase in cAMP response was measured at each concentration of $\mathrm{CT}$, the same differences between $\mathrm{H}_{4}$ or tsHFIE versus $\mathrm{T}_{84}$ was maintained (Fig. $3 B$ ). In contrast, we used forskolin to directly activate adenylate cyclase in the cell, and cAMP production after forskolin stimulation was the same in both $\mathrm{H}_{4}$ and $\mathrm{T}_{84}$ cells ( $366.03 \pm 186$ versus $\left.359.34 \pm 177 \mathrm{pmol} / \mathrm{mg}\right)$, 

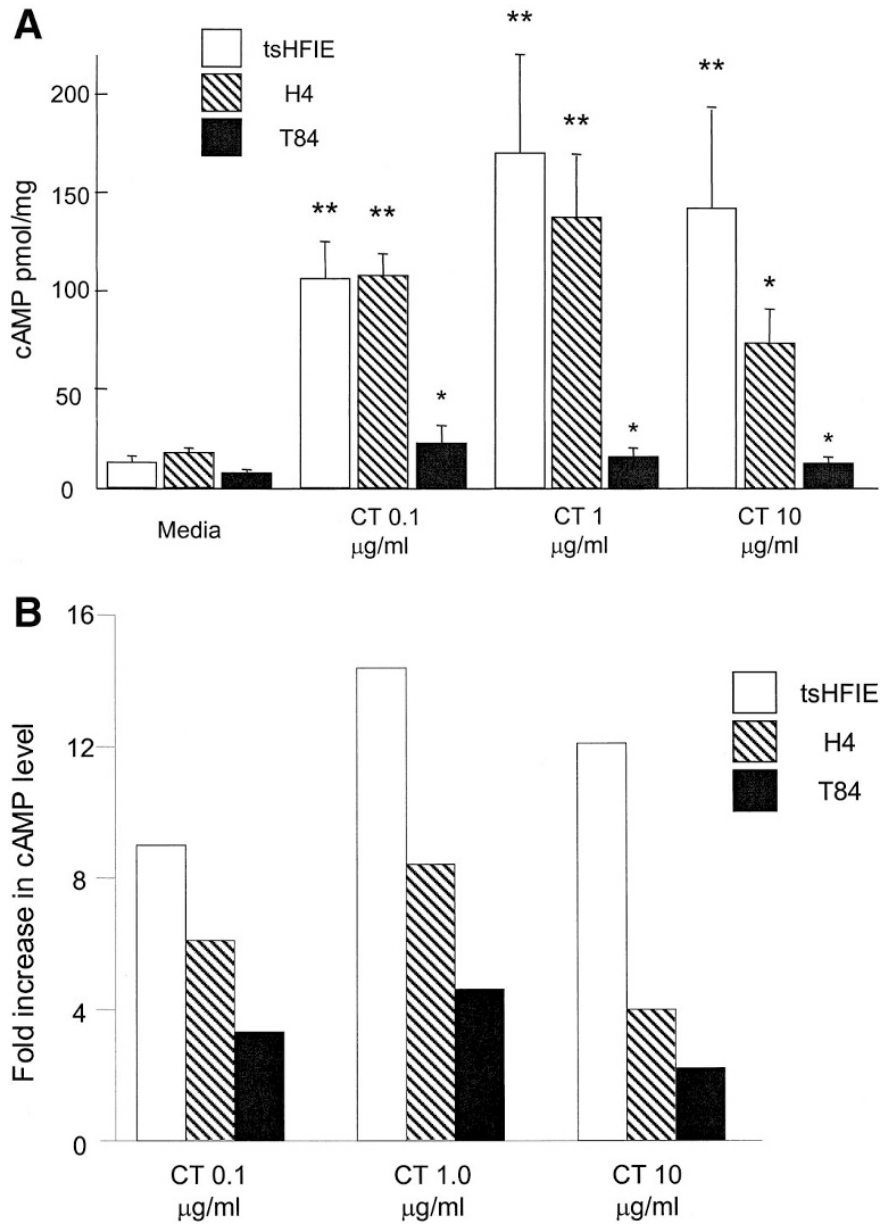

Figure 3. $A$, effect of $\mathrm{CT}$ on intracellular cAMP production in immature $v s$ mature human enterocytes. Human fetal small intestinal cell lines $\left[\mathrm{H}_{4}\right.$ (畻) and tsHFIE $(\square)$ cells] as well as $\mathrm{T}_{84}$ cells $(\square)$ were stimulated either with various concentrations of CT or media alone for $1 \mathrm{~h}$. Cellular cAMP levels were measured and expressed as picomoles per milligram of total protein. ${ }^{*} p<$ $0.05, * * p<0.01$. B, effect of CT on intracellular cAMP as determined by a fold increase in $\mathrm{H}_{4}(\mathbb{Q})$, tsHFIE $(\square)$, and $\mathrm{T}_{84}(\square)$ cells. All cell lines were stimulated either with various concentrations of CT or with media alone for $1 \mathrm{~h}$. Cellular cAMP level was measured and expressed as a fold increase over baseline. There is a consistently higher fold increase in cellular cAMP in $\mathrm{H}_{4}$ and tsHFIE cells compared with $\mathrm{T}_{84}$ cells.

suggesting a specific CT-induced developmental response. We feel justified in comparing the $\mathrm{CT}$ response in $\mathrm{H}_{4}$ and tsHFIE cells with that of confluent $\mathrm{T}_{84}$ cells because a similar response was noted in fetal versus infant or child small intestine as a comparison. In previous studies we have shown that $\mathrm{H}_{4}$ and tsHFIE cells respond differently to an inflammatory stimulus compared with Caco-2, $\mathrm{T}_{84}$, or HT29 cells $(19,20)$, and the same difference was noted when comparing intestinal biopsy samples from fetal and infant or child small intestine.

Organ cultures and xenografts. To confirm the differences found in cAMP activation after CT stimulation between immature and mature cell lines, tissues from human fetal small intestine xenografts exposed to CT were examined for cAMP levels and compared with those obtained from small intestinal biopsies in infants or older children exposed to CT. Our data showed CT induced a cAMP accumulation in these tissues, and that the CT-induced response was greater in fetal small intes- tine xenografts compared with small intestine biopsies from children. Figure 4 shows the results of these studies.

\section{DISCUSSION}

These studies for the first time provide direct preliminary experimental evidence that $\mathrm{CT}$ stimulation results in an excessive chloride secretion in immature compared with mature human small intestine. In addition, the studies suggest that secretion appears to be developmentally regulated and in part related to an excessive cAMP production in response to CT. These observations made in the human fetal small intestine correspond to comparable observations previously reported from this laboratory $(4,6,7,18)$ in animal models. A similar enhanced intracellular response to bacterial endotoxin in the immature (fetal) human small intestine has previously been reported in studies involving an exogenous bacterial inflammatory mediator, lipopolysaccharide and an endogenous mediator, IL- $1 \alpha$. In these studies a much greater IL- 8 response was noted in $\mathrm{H}_{4}$ cells compared with Caco- 2 cells, suggesting a developmentally regulated intracellular activation of the cytokine (20). These observations were validated by a similar IL-8 differential response to lipopolysaccharide and IL- $1 \alpha$ in organ cultures of fetal and infant or child intestine. This previous observation adds credence to the observations made in this study.

To provide these observations, we have had to use various models for the developing small human intestine. Two human

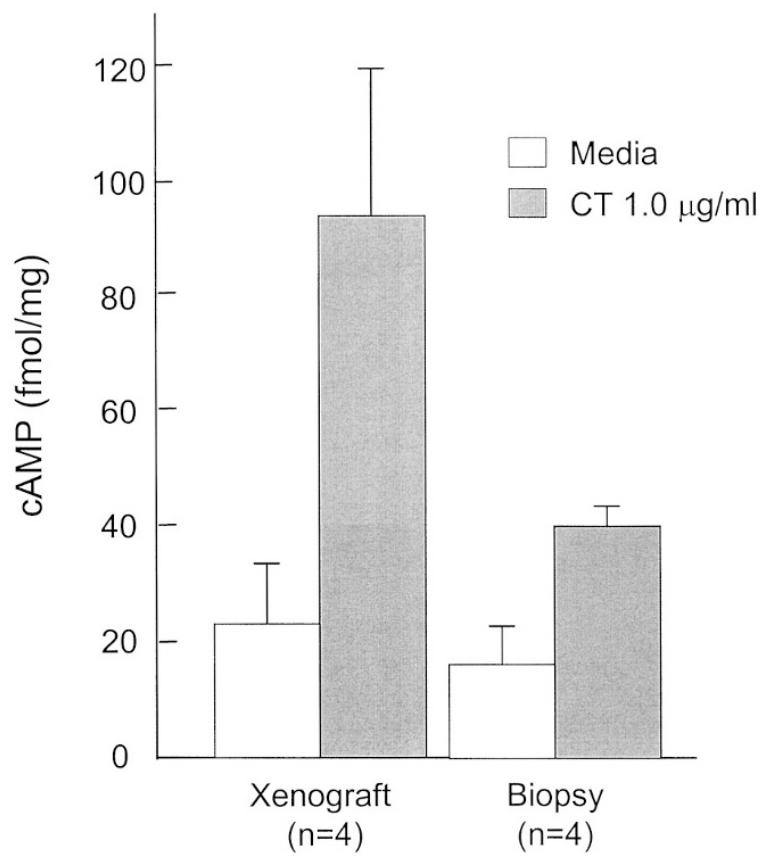

Figure 4. Effect of CT on intracellular cAMP production in fetal xenograft organ cultures $v s$ a biopsy organ cultures from children at various ages. Human intestinal samples either from human fetal small intestine xenografts $(n=4)$ or pediatric small intestine biopsies $(n=4)$ were incubated with CT ( $\square$ ) or media alone $(\square)$ for $2 \mathrm{~h}$. Cellular cAMP was extracted using a solid-phase method and measured. The level of cAMP is expressed as femtomoles per milligram total protein. Data show an increase in cAMP production after CT stimulation in both tissues, but the CT response is much greater in fetal small intestine xenograft organ cultures. This observation confirms the studies in intestinal cell lines. 
fetal small intestinal cell lines ( $\mathrm{H}_{4}$ and tsHFIE) have been used in this laboratory to determine in vitro responses of the developing intestine to microbial flora and their toxins. The cellular cAMP responses to $\mathrm{CT}$ in both cell lines (representative immature enterocytes) have been compared with confluent $\mathrm{T}_{84}$ monolayers (representative mature enterocytes) in this study, and the comparison was validated using organ cultures of immature and mature small intestine. To test for chloride secretion in response to $\mathrm{CT}$ stimulation in immature versus mature human small intestine, a previously reported microUssing chamber technique (9) was validated. This technique enabled us to use tiny quantities of an intestinal mucosa biopsy to measure enterocyte resistance and $I_{s c}$ when CT was applied to the mucosal surface. A change in $I_{s c}$ corresponds to a quantitative measurement of chloride secretion.

To validate this technique as an accurate developmental measure of the CT response, we used small intestinal mucosa from preweaned and postweaned rats in the micro-Ussing chamber. Using in vivo small intestinal loops, we have previously reported (4) that fluid secretion in preweaned small intestine was much greater than in postweaned small intestine. In these studies a similar excessive response to CT stimulation (increased $I_{s c}$; Fig. 1) was noted in preweaned versus postweaned rat small intestine. Based on this validation, we believed that this technique could be used to study the developmental secretory response in human small intestine.

Furthermore we have validated an established a technique for xenograft transplantation of fetal human intestine into the s.c. capsule of SCID mice (13). Once small intestinal loops of fetuses of gestational age 16-20 wk are transplanted into the s.c. capsule, a reepithelialization occurs and they develop in a manner similar to that predicted for the third trimester of human gestation in utero $(16,17)$. Fetal human xenografts can be isolated and exposed to $\mathrm{CT}$ and then used to measure cAMP accumulation. Therefore in this study, we have used models of human small intestinal development, (e.g. intestinal organ culture and fetal small intestinal xenograft transplantation) to confirm the noted increase in cAMP response to CT stimulation observed in fetal human versus mature human cell lines (Figs. 3 and 4). We believe the collective use of these techniques provides compelling evidence that the fetal enterocyte secretory response to CT stimulation is accentuated versus the mature enterocyte and at least in part is developmentally regulated vis-à-vis an enhanced cAMP response. As we have not measured CT receptor number and affinity or developmental expression of CFTR in these studies, we cannot conclude that this observation is the only explanation for the enhanced CT-stimulated secretion in immature human intestine.

In the last decade a number of important studies have suggested that CT can mediate chloride secretion by means other than the classically described pathway (2). For example, CT can interact with receptors on enteroendocrine cells to cause the release of 5-hydroxytryptamine and prostaglandins (e.g. $\left.\mathrm{PGE}_{2}\right)$. By interacting with the enteric nervous system, these mediators can affect release of the neuropeptide vasoactive intestinal polypeptide at enteric nerve endings juxtaposed to crypt cell enterocytes. Vasoactive intestinal polypeptide may in turn activate cAMP through its own basolateral receptor to mediate chloride secretion (21-23). Alternatively, 5-hydroxytryptamine and $\mathrm{PGE}_{2}$ may directly stimulate chloride secretion through an as yet unidentified pathway in enterocytes (24). These alternative mechanisms of CT action may explain the extent of the muted secretory responses we observed using the micro-Ussing chamber compared with that reported using an in vivo loop model in rat small intestine. However, studies have demonstrated a nonneural effect of CT on chloride secretion in isolated small intestinal mucosa in vitro (25). Thus the microUssing chamber technique is a valuable technique that permits us to characterize a single CT-mediated chloride secretion process. Furthermore, the micro-Ussing chamber will allow us to quantify chloride secretion in response to CT from human small intestine biopsy tissue and human fetal intestine xenografts as models of human gut development. By using these techniques collectively, including in vitro cellular studies, we should be able to characterize the developmental mechanism(s) contributing to the differentiated CT response in immature compared with mature human enterocytes. Preliminary data using $\mathrm{PGE}_{2}$ (Fig. $1 B$ ) in this study to compare effects in preweaned and postweaned rats suggest that the $\mathrm{PGE}_{2}-$ stimulated chloride secretion is not developmentally regulated. Additional, more-comprehensive studies are needed to finalize this observation.

Previous studies have shown that developmental changes in membrane structure that influence binding affinities but not receptor densities may, in part, contribute to the increased sensitivity of suckling rats to CT (6). However, the relatively small differences in binding to cell surface receptors suggested that a subsequent postreceptor mechanism may account for a greater part of the observed developmental difference noted in the cellular response (7). CT induces secretion by activation of the adenylyl cyclase signaling cascade, resulting in increased levels of the cellular second messenger cAMP (26). The increase in cAMP and activation of the chloride channel is thought to be the principal mechanism for the pathologic actions of CT. Heretofore, most of the studies on CT activation of adenylate cyclase have been carried out in cells other than intestinal enterocytes or in animal enterocytes. A study such as this, which addresses the cellular mechanism of a developmentally different $\mathrm{CT}$ response in human enterocytes, seems particularly advisable as little is known of the mechanisms by which human immature enterocytes respond to CT. As stated, we used two well-established human fetal intestinal epithelial cell lines, $\mathrm{H}_{4}$ and tsHFIE, and compared responses to the $\mathrm{T}_{84}$ cell line as prototypes of immature and mature human enterocytes. We have found that, when incubated with $\mathrm{CT}, \mathrm{H}_{4}$ cells generate a significantly higher level of intracellular cAMP compared with $\mathrm{T}_{84}$ cells (Fig. 3). Furthermore the differences in intracellular cAMP levels are not the result of a generalized reduced capacity of adenylate cyclase to convert ATP to cAMP because both cell types have shown a similar level of cAMP increase after incubation with a supramaximal dose of forskolin, a generic cAMP ligand. This preliminary observation suggests that the developmental response of cAMP to CT stimulation may be specific and not a generalized overreaction to all cAMP-stimulating ligands. Further, more-extensive studies are needed using other ligands to confirm this observation. 
Activation of the apical chloride ion channel is stimulated by agonists that increase the cellular cAMP level. The increase in cAMP results in activation of a cAMP-dependent protein kinase A, which modulates actions of target proteins by phosphorylating cellular substrates, including the CFTR (27). CFTR is the most clearly identified chloride channel in the intestinal epithelium. The importance of this protein is evident from the observation that the secretory responses to many agonists including $\mathrm{CT}$ is absent in cystic fibrosis $(28,29)$. Because both $\mathrm{H}_{4}$ and $\mathrm{T}_{84}$ cells express CFTR by reverse transcription-PCR and by immunoprecipitation (data not shown) and other investigators have shown there is a direct correlation between an increased level of cellular cAMP and CT-induced chloride secretion in an intestinal epithelia HT29 cl 19A cell monolayer (30), we have reason to believe the elevation of cAMP is correlated with chloride secretion in response to $\mathrm{CT}$ in these two cell lines. We speculate that the secretory response to $\mathrm{CT}$ in $\mathrm{H}_{4}$ cells is more sensitive than that of $\mathrm{T}_{84}$ cells.

It is possible that the excessive secretory response in fetal enterocytes reported in this study may also be a result of other increased developmentally regulated intracellular steps, including the protein kinase A response or an increased expression of CFTR developmentally. We plan experiments to determine whether additional developmentally regulated intracellular processes contribute to the enhanced CT-stimulated secretion.

\section{CONCLUSIONS}

This study represents an initial preliminary observation in human fetal cells that the CT-stimulated secretory response is developmentally regulated and involves in part the cAMP signal transduction pathway. What remain to be determined are the precise developmental events that regulate the maturation of cellular signaling and the response to CT. From the preliminary data presented, the enhanced cAMP activation appears to be $\mathrm{CT}$ specific. In a more global sense, the use of $\mathrm{CT}$ as a probe to examine developmental regulation of secretion in human fetal enterocytes may represent an important paradigm for our understanding the development of microbial-human enterocyte interactions in general, as previously reported from this laboratory (20), and provide insights into mucosal barrier function in the extrauterine environment. Moreover, these studies may lead to a better understanding of the pathophysiology of cholera toxigenic diarrhea in infants and may better enable us to prevent or treat this and other age-related intestinal infectious diseases.

\section{REFERENCES}

1. Snyder JD, Merson MH 1982 The magnitude of the global problem of acute diarrheal disease: a review of active surveillance data. Bull World Health Organ 60:605-613

2. Chu SW, Walker WA 1993 Bacterial toxin interaction with the developing intestine: a possible explanation for toxogenic diarrhea of infancy. Gastroenterology 104:916925

3. Field M, Rao MC, Chang EB 1989 Intestinal electrolyte transport and diarrheal disease. N Engl J Med 321:879-883

4. Chu SW, Ely IG, Walker WA 1989 Age and cortisone alter host responsiveness to cholera toxin in the developing gut. Am J Physiol 256:G220-G226

5. Cohen MB, Moyer MS, Luttrell M, Giannella RA 1986 The immature rat small intestine exhibits an increased sensitivity and response to Escherichia coli heat-stable enterotoxin. Pediatr Res 20:555-560

6. Lencer WI, Chu SW, Walker WA 1987 Differential binding kinetics of cholera toxin to intestinal microvillus membrane during development. Infect Immun 55:3126-3130

7. Seo JK, Chu SW, Walker WA 1989 Development of intestinal host defense: an increased sensitivity in the adenylate cyclase response to cholera toxin in suckling rats. Pediatr Res 25:225-227

8. Raufman J-P 1997 Cholera. Am J Med 104:386-394

9. Pratha VS, Thompson SM, Hogan DL, Paulis P, Dreilinger AD, Barrett KE, Isenberg JI 1998 The utility of endoscopic biopsies to quantitate the human duodenal ion transport. J Lab Clin Med 132:512-518

10. Sanderson IR, Ezzell RM, Kedinger M, Erlanger M, Xu Z, Pringault E, Leon-Robine S, Louvard D, Walker WA 1996 Human fetal enterocytes in vitro: modulation of the phenotype by extracellular matrix. Proc Natl Acad Sci USA 93:7717-7722

11. Quaroni A, Beaulieu JF 1997 Cell dynamics and differentiation of conditionally immortalized human intestinal epithelial cells. Gastroenterology 113:1198-1213

12. Autrup H 1980 Explant culture of human colon. Methods Cell Biol 21B:385-401

13. Savidge TC, Morey AL, Ferguson DJP, Leming KA, Shmakov AN, Phillips AD 1995 Human intestinal development in a severe-combined immunodeficient xenograft model. Differentiation 56:361-371

14. Ussing HH, Zerahn K 1999 Active transport of sodium as the source of electric current in the short-circuited isolated frog skin. [Reprinted from Acta. Physiol Scand 1951;123:110-127] J Am Soc Nephrol 10:2056-2065

15. Quaroni A, Wands J, Trelstad RL, Isselbacher KJ 1979 Epithelial cell cultures from rat small intestine. J Cell Biol 80:245-265

16. Buisane MP, Aubert JP, Walker WA, Savidge TC 2003 Developmental patterns of mucin gene expression in human fetal small intestinal xenografts maintained in severe-combined immunodeficient mice. Pediatr Res, in press

17. Nanthakumar NN, Klopcic, Walker WA 2003 Normal glucocorticoid induced development of the human small intestinal xenograft. Am J Physiol (in press)

18. Sanderson IR, Xu Z, Chu SW, Xie QY, Levine L, Walker WA 1996 Developmental differences in the stimulatory GTP binding protein subunit (Gs $\alpha$ ) for adenylate cyclase in the rat small intestine. Gut 38:853-858

19. Claud EC, Savidge T, Walker WA 2003 Modulation of human intestinal epithelial cell interleukin- 8 secretion by human milk factors. Pediatr Res (in press)

20. Nanthakumar N, Fusunyan RD, Sanderson IR, Walker WA 2000 Inflammation in the developing human intestine: a possible pathophysiologic basis for necrotizing enterocolitis. Proc Natl Acad Sci USA 97:6043-6048

21. Jodal M, Lundgren O 1995 Nerves and cholera secretion. Gastroenterology 108:287288

22. Jodal M, Holmgren S, Lundgren O, Sjöqvist 1993 Involvement of the myenteric plexus in cholera toxin-induced net fluid secretion in the rat small intestine. Gastroenterology 105:1286-1293

23. Mourad FH, Nassar CF 2000 Effect of vasoactive intestinal polypeptide (VIP) antagonism on rat jejunal fluid and electrolyte secretion induced by cholera and Escherichia coli enterotoxins. Gut 47:382-386

24. Beubler E, Kollar G, Saria A, Bukhave K, Rask-Madsen J 1989 Involvement of 5-hydroxytryptamine, prostaglandin $\mathrm{E}_{2}$ and cyclic adenosine monophosphate in cholera toxin-induced fluid secretion in the small intestine of the rat in vivo. Gastroenterology 96:368-376

25. Burleigh DE, Borman RA 1997 Evidence for a nonneural electrogenic effect of cholera toxin on human isolated ileal mucosa. Dig Dis Sci 42:1964-1968

26. Dominguez P, Barros F, Lazo PS 1985 The activation of adenylate cyclase from small intestinal epithelium by cholera toxin. Eur J Biochem 146:533-538

27. Taylor SS 1989 cAMP-dependent protein kinase. Model for an enzyme family. J Biol Chem 264:8443-8446

28. Hansson GC 1988 Cystic fibrosis and chloride-secreting diarrhoea. Nature 333:711

29. Quinton PM 1999 Physiological basis of cystic fibrosis: a historical perspective. Physiol Rev 79(suppl):S3-S22

30. Nath SK, Huang X, L'helgoualc'h A, Rautureau M, Bisalli A, Heyman M, Desjeux JF 1994 Relation between chloride secretion and intracellular cyclic adenosine monophosphate in a cloned human intestinal cell line HT-29 cl 19A. Gut 35:631-636 